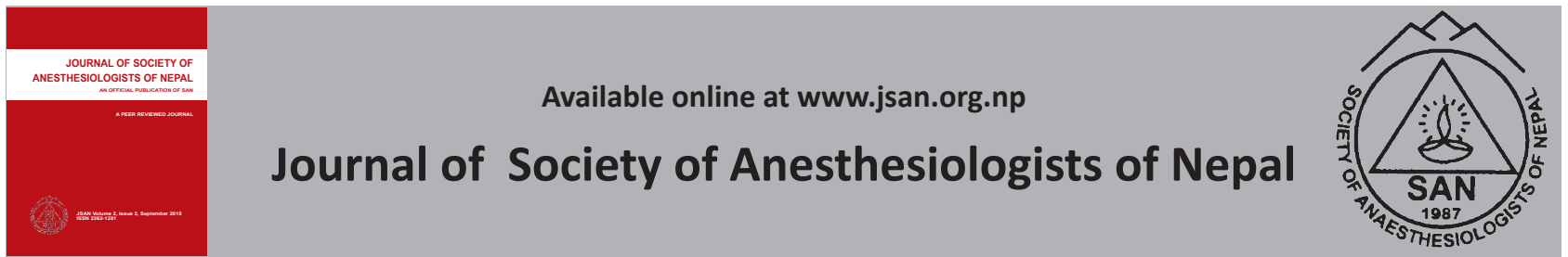

Original article

\title{
Perception of the new post graduate students of anaesthesiology about the speciality - a questionnaire based cross-sectional survey
}

Sudeshna Bhar (Kundu) ${ }^{\epsilon}$, Anisha De ${ }^{\epsilon}$, Debasish Bhar ${ }^{*}$, Chiranjib Bhattacharyya ${ }^{\epsilon}$, Suchismita Pal ${ }^{€}$, Chaitali $^{\prime}$

Biswas $^{\epsilon}$, Sankari Santra ${ }^{\epsilon}$, Sunanda Maji ${ }^{*}$

${ }^{€}$ Institute of Post Graduate Medical Education \& Research, 244 A.J.C. Bose Road, Kolkata, West Bengal, India

${ }^{¥}$ Midnapore Medical College, Vidyasagar Rd, Medinipur, West Bengal, India

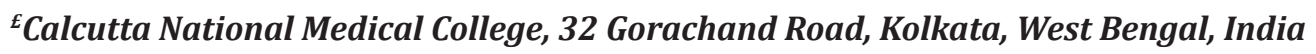

\author{
ARTICLE I NFO \\ Article History \\ Received 17.06.2015 \\ Accepted 23.08.2015 \\ Published 10.09.2015 \\ (C) Authors retain copyright \\ and grant the journal right \\ of first publication with the \\ work simultaneously licensed \\ under a Creative Commons \\ Attribution License that allows \\ others to share the work with \\ an acknowledgement of the \\ work's authorship and initial \\ publication in this journal.
}

\begin{abstract}
Background: Previous studies revealed that the undergraduate medical students have a poor perception about the anaesthesiologists. But, there is paucity of such studies on the postgraduate students. Therefore, this study was conducted to evaluate the perception of the first year post graduate students pursuing anaesthesiology on various professional aspects of this speciality.

Methods: A questionnaire-based anonymous cross-sectional survey was conducted on 63 first year postgraduate students of anaesthesiology from seven medical colleges under the West Bengal University of Health Sciences. Data were collected from the students on the day of admission. The questionnaire elicited information on demographic characteristics, functions and health hazards of anaesthesiologists and perception of students about this discipline. The responses were sorted out, coded and analyzed.
\end{abstract}

Results: Involvement in the intra-operative period (84\%), critical care (58\%), and chronic pain management (40\%) were recognized as major functions of an anaesthesiologist. Their role in preoperative and postoperative care was appreciated only by $16 \%$ and $18 \%$ students respectively. $48 \%$ students mentioned ignorance about health hazards associated with practise of anaesthesiology. They considered this discipline stressful, dependent and unrecognised.

Conclusions: This study concludes that there exists an inconsistent perception of the roles of anesthesiologists among the new post graduate students. It specifically identifies various potential areas to improve student's awareness regarding the widespread domain of this discipline.

Keywords: anaesthesiology; perception; postgraduate education

How to cite this article: Bhar (Kundu) S, De A, Bhar D, Bhattacharyya C, Pal S, Biswas C, Santra S, Maji S.Perception of the new post graduate students of anaesthesiology about the speciality - a questionnaire based cross-sectional survey. JSAN 2015;2:67-72.

Corresponding author: Sudeshna Bhar (Kundu), MD

Assistant Professor, Department of Anaesthesiology,

Institute of Post Graduate Medical Education \& Research

244A, Acharya Jagadish Chandra Bose Road, Kolkta-700020

Telephone: +919836048916,Email -sudeshna04cmc@yahoo.co.in 


\section{Introduction}

Anaesthesiology is one of the important branches of medical science that has undergone immense development in the last few decades. It is an upcoming multimodal specialty. Apart from the crucial involvement in the operating room, anaesthesiologists play a very vital role in the intensive care units, trauma care, resuscitation and pain management. But, unfortunately, these dynamic roles remain unknown to the patients ${ }^{1,2}$ as well as to the non-anaesthesiologist medical persons $\mathrm{s}^{3-5}$. A survey in Canada found that the role of the anaesthesiologists in fluid management, resuscitation, acute and chronic pain management remain unknown to most of the undergraduate students. ${ }^{3}$ Another survey on medical students revealed that anaesthesiology was considered as unchallenging, non-lucrative, stereotyped and dependant speciality. The job of the anaesthesiologists also remained unrecognized. ${ }^{4}$

Most of the previous studies were conducted on the undergraduate students in the western world. Moreover, the undergraduate students might have a poor knowledge of this speciality because of limited exposure and lack of interest in this discipline. On the other hand, the postgraduate students or the qualified anaesthesiologists already have a clear perception about this subject. We conducted this study on the new first year postgraduate students who have decided to pursue this subject, but not yet exposed to this speciality at the postgraduate level.

We aim to evaluate the perception of the first year post graduate students pursuing anaesthesiology on various professional aspects of this speciality.

\section{Methods}

This questionnaire-based anonymous cross-sectional survey was conducted on the students of seven medical colleges who had just joined the postgraduate anaesthesiology curriculum under the West Bengal University of Health Sciences, Kolkata, India. Approval was taken from the Institutional Ethical Committee. Written informed consent was obtained from each student. A semi-structured printed questionnaire was given to each student personally by the members of the research team on the day of joining to the department of Anaesthesiology.

Data were collected from the students on the day of admission before they started performing their duties as post graduate students. The content of the questionnaire and the closed ended responses were designed after a thorough internet search on indexed articles of similar academic interest followed by an expert clinical guess to adjust the responses accordingly. The first part of the questionnaire elicited information on demographic characteristics like age, sex and type of the postgraduate course pursued. Second part of the questionnaire was related to the functions and health hazards of an anaesthesiologist. The third part of the questionnaire consisted of closed ended response to elicit information on the perception of the students about this discipline.

Students wrote or marked their responses on the questionnaire sheet. The responses of each student were received in sealed envelopes by the members of the research team personally. The identity and survey information of each respondent were kept confidential.

After data collection, questionnaires were manually sorted out and coded. Data were entered into a Microsoft Excel Spreadsheet and were analysed using SPSS and Statistica softwares. Categorical data were expressed in percentages. The distribution of responses to individual items in the questionnaire was compared between residents choosing anaesthesiology as their first preference versus those not choosing the subject as first preference by Fischer exact test or Chi square test as applicable. In case Chi square test prerequisites were not fulfilled, Fischer Exact test was applied to $3 \times 2$ tables with its Freeman-Halton extension (www.vassarstats.net). All tests were 2 tailed. A P value of $<0.05$ was considered statistically significant.

\section{Results}

Questionnaires were distributed among 63 first year postgraduate students pursuing anaesthesiology. Response rate was $100 \%$. Thirteen students had previous exposure to anaesthesiology, nine students did house job and four students had postgraduate diploma (DA) in this subject. These 13 students were excluded from the study and finally data collected from rest of the students ( $\mathrm{n}=$ 50) were analysed. The demographic data obtained are tabulated below (Table 1).

Table 1: Distribution of age, sex, course of the study, previous exposure to anaesthesia and pursuing anaesthesiology as subject of first choice

\begin{tabular}{ll}
\hline Demographic profile & $\begin{array}{l}\text { Number (\%) of } \\
\text { students }\end{array}$ \\
\hline $\begin{array}{l}\text { (i) Age (years) } \\
\text { (ii) Sex } \\
\text { Male }\end{array}$ & 34.14 (mean value) \\
Female & $16(32 \%)$ \\
(iii) Course of the study & \\
MD & $35(70 \%)$ \\
DA & $15(30 \%)$ \\
(iv) Anaesthesiology pursued & \\
as subject of first choice in \\
post graduate curriculum \\
$\quad$ Yes & $14(28 \%)$ \\
No & $36(72 \%)$ \\
\hline
\end{tabular}

Various functions of the anaesthesiologists as mentioned by the students are mentioned in Figure 1 . Most of the 
students (84\%) mentioned that the main function of an anaesthesiologist is to provide anaesthesia during surgery in the operating room. The anaesthesiologist's participation in the preoperative and postoperative management of a patient is appreciated only by eight (16\%) and nine (18\%) students respectively. Twenty (40\%) students thought anaesthesiologist play important role in the pain management. Twenty nine (58\%) students ascribed the role of critical care to the anaesthesiologists.

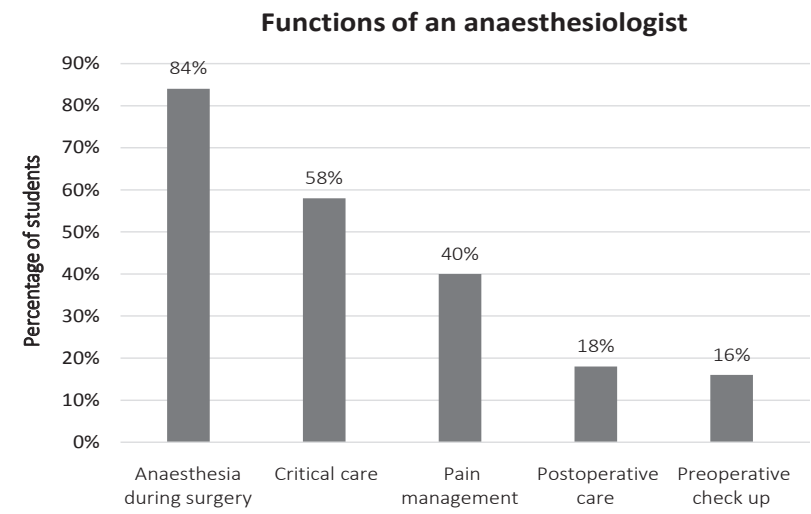

Figure 1: Functions of the anaesthesiologists

Figure 2 shows various health hazards of the anaesthesiologists as mentioned by the students. Twenty four (48\%) students mentioned that they did not know about any health hazards associated with the practise of anaesthesiology. Inhalation of anaesthetic gases and substance abuse were considered as the important health hazard only by three (6\%) students. Needle prick injury, depression, megaloblastic anaemia and backache, each of these hazads was mentioned by two (4\%) students.

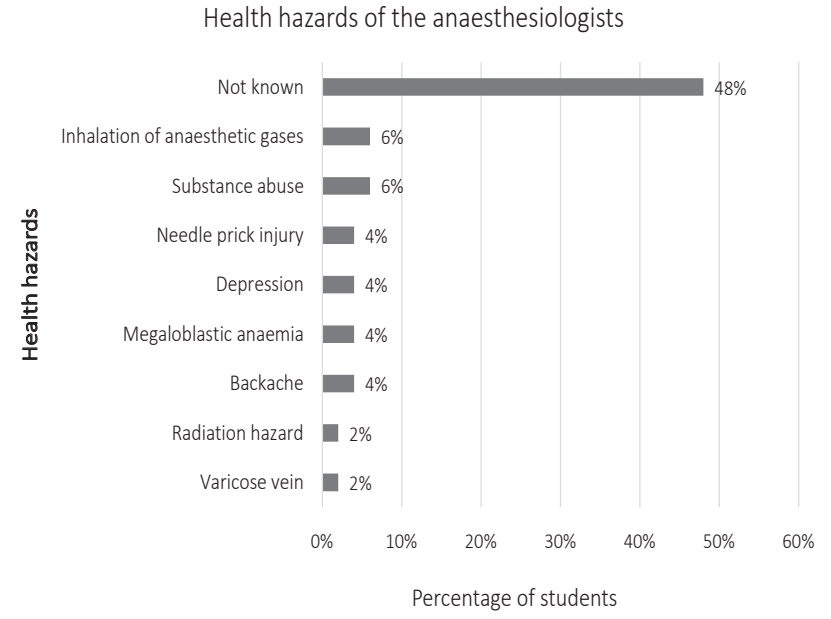

Figure 2: Health hazards of anaesthesiologists

Table 2 shows the perception of the students about the practice of anaesthesiology. It shows the response of all students as well as those choosing the subject as first preference. Majority of the students (74\%) stated that preoperative optimisation of a patient with cardiac disease should be done by a cardiologist. The possibility of lawsuit and workload of postgraduate students were considered similar to their surgical counterparts. Their role in fluid management, trauma care and communication with the patient and their relatives were well recognised. But their role in administration and research were not well perceived. They considered this subject dependent, stressful and unrecognised. 


\begin{tabular}{|c|c|c|c|c|c|}
\hline \multirow[t]{3}{*}{ Questions } & \multirow[t]{3}{*}{ Response } & \multirow{3}{*}{$\begin{array}{l}\text { Total number } \\
\text { of students } \\
(n=50)\end{array}$} & \multicolumn{2}{|c|}{$\begin{array}{l}\text { Choose anaesthesiology as the } \\
\text { subject of first preference }\end{array}$} & \multirow[t]{3}{*}{$p$ value } \\
\hline & & & Yes & No & \\
\hline & & & $(n=14)$ & $(n=36)$ & \\
\hline \multirow{3}{*}{$\begin{array}{l}\text { 1. Preoperative optimization of } \\
\text { a patient with cardiac disease } \\
\text { should ideally be done by }\end{array}$} & Anaesthesiologist & $13(26 \%)$ & $4(29 \%)$ & $9(25 \%)$ & \multirow[t]{3}{*}{1.000} \\
\hline & Cardiologist & $37(74 \%)$ & $10(71 \%)$ & $27(75 \%)$ & \\
\hline & Surgeon & $0(0 \%)$ & $0(0 \%)$ & $0(0 \%)$ & \\
\hline \multirow{3}{*}{$\begin{array}{l}\text { 2. The degree of mental stress } \\
\text { of an anaesthesiologist in } \\
\text { comparison to that of his/her } \\
\text { surgical colleague is }\end{array}$} & More & $30(60 \%)$ & 13(93\%) & $17(47 \%)$ & \multirow[t]{3}{*}{0.010} \\
\hline & Same & $13(26 \%)$ & $0(0 \%)$ & $13(36 \%)$ & \\
\hline & Less & $7(4 \%)$ & $1(7 \%)$ & $6(17 \%)$ & \\
\hline \multirow{3}{*}{$\begin{array}{l}\text { 3. The possibility of lawsuit } \\
\text { against an anaesthesiologist in } \\
\text { comparison to that of his or her } \\
\text { surgical colleague is }\end{array}$} & More & $16(32 \%)$ & $7(50 \%)$ & $9(25 \%)$ & \multirow[t]{3}{*}{0.534} \\
\hline & Same & $27(54 \%)$ & $7(50 \%)$ & $20(56 \%)$ & \\
\hline & Less & $7(14 \%)$ & $0(0 \%)$ & $1(19 \%)$ & \\
\hline \multirow{3}{*}{$\begin{array}{l}\text { 4. The workload of a PGT of } \\
\text { anaesthesiology in comparison } \\
\text { to that of a PGT of other clinical } \\
\text { discipline is }\end{array}$} & More & $18(36 \%)$ & $5(36 \%)$ & $13(36 \%)$ & \multirow[t]{3}{*}{0.997} \\
\hline & Same & $21(42 \%)$ & $6(43 \%)$ & $15(42 \%)$ & \\
\hline & Less & $11(22 \%)$ & $3(21 \%)$ & $8(22 \%)$ & \\
\hline \multirow{3}{*}{$\begin{array}{l}\text { 5. Are anaesthesiologists } \\
\text { dependants on their surgical } \\
\text { colleagues? }\end{array}$} & Yes & $28(56 \%)$ & $7(50 \%)$ & $21(58 \%)$ & \multirow[t]{3}{*}{0.254} \\
\hline & No & $18(36 \%)$ & $7(50 \%)$ & $11(31 \%)$ & \\
\hline & Not known & $4(8 \%)$ & $0(0 \%)$ & $4(11 \%)$ & \\
\hline \multirow{3}{*}{$\begin{array}{l}\text { 6. Does anaesthesiologist have } \\
\text { any role in the post operative fluid } \\
\text { management of a patient? }\end{array}$} & Yes & $47(94 \%)$ & $14(100 \%)$ & $33(92 \%)$ & \multirow[t]{3}{*}{0.550} \\
\hline & No & $0(\%)$ & $0(0 \%)$ & $0(0 \%)$ & \\
\hline & Not known & $3(6 \%)$ & $0(0 \%)$ & $3(8 \%)$ & \\
\hline \multirow{3}{*}{$\begin{array}{l}\text { 7. Does anaesthesiologist play } \\
\text { a vital role in trauma care } \\
\text { management? }\end{array}$} & Yes & 49(98\%) & $14(100 \%)$ & $35(97 \%)$ & \multirow[t]{3}{*}{1.000} \\
\hline & No & $0(0 \%)$ & $0(0 \%)$ & $0(0 \%)$ & \\
\hline & Not known & $1(2 \%)$ & $0(0 \%)$ & $1(3 \%)$ & \\
\hline \multirow{3}{*}{$\begin{array}{l}\text { 8. Can an anaesthesiologist be in- } \\
\text { charge of hospital administration? }\end{array}$} & Yes & $31(62 \%)$ & $10(71 \%)$ & $21(58 \%)$ & \multirow[t]{3}{*}{0.522} \\
\hline & No & $0(0 \%)$ & $0(0 \%)$ & $0(0(\%)$ & \\
\hline & Not known & $19(38 \%)$ & $4(29 \%)$ & $15(42 \%)$ & \\
\hline \multirow{3}{*}{$\begin{array}{l}\text { 9. Can cardiopulmonary } \\
\text { resuscitation (CPR) be performed } \\
\text { without the help of an } \\
\text { anaesthesiologist? }\end{array}$} & Yes & $30(60 \%)$ & $7(50 \%)$ & $23(64 \%)$ & \multirow[t]{3}{*}{0.460} \\
\hline & No & $1(30 \%)$ & $6(43 \%)$ & $9(25 \%)$ & \\
\hline & Not known & $5(10 \%)$ & $1(7 \%)$ & $4(11 \%)$ & \\
\hline \multirow{3}{*}{$\begin{array}{l}\text { 10. Can PhD be done in } \\
\text { anaesthesiology? }\end{array}$} & Yes & $16(32 \%)$ & $7(50 \%)$ & $9(25 \%)$ & \multirow[t]{3}{*}{0.105} \\
\hline & No & $0(0 \%)$ & $0(0 \%)$ & $0(0 \%)$ & \\
\hline & Not known & $34(68 \%)$ & $7(50 \%)$ & $27(75 \%)$ & \\
\hline 11. Does anaesthesiologist meet & Yes & $6(12 \%)$ & $0(0 \%)$ & $6(17 \%)$ & 0.258 \\
\hline & No & $4(82 \%)$ & 13(93\%) & $28(78 \%)$ & \\
\hline & Not known & $3(6 \%)$ & $1(7 \%)$ & $2(5 \%)$ & \\
\hline 12. Is communication with & Yes & $43(86 \%)$ & $14(100 \%)$ & $29(81 \%)$ & 0.322 \\
\hline $\begin{array}{l}\text { patient's relatives necessary for an } \\
\text { anaesthesiologist? }\end{array}$ & No & $4(8 \%)$ & $0(0 \%)$ & $4(11 \%)$ & \\
\hline & Not known & $3(6 \%)$ & $0(0 \%)$ & $3(8 \%)$ & \\
\hline 13. Do you think that the work of & Yes & $22(44 \%)$ & $7(50 \%)$ & $15(42 \%)$ & 0.788 \\
\hline $\begin{array}{l}\text { the anaesthesiologists remains } \\
\text { unrecognised? }\end{array}$ & No & $18(36 \%)$ & $5(36 \%)$ & $13(36 \%)$ & \\
\hline & Not known & $10(20 \%)$ & $2(14 \%)$ & $8(22 \%)$ & \\
\hline
\end{tabular}




\section{Discussion}

The role of the anaesthesiologists is not always well appreciated beyond the realms of operating room. It is unfortunate that this negative impression is widely prevalent among the medical profession also. Brief and late exposure to this speciality may be cited as the contributing factors. ${ }^{3,6}$ However recently, awareness for this subject is growing as the anaesthesiologists are gradually coming out from behind the curtains of the operating room into the forefront of patient care. Their dynamic roles have extended from preoperative evaluation, patient counselling to postoperative follow up, trauma care, critical care, resuscitation and chronic pain management. But the diverse nature of this subject still remains unexplored to most of the undergraduate medical students. ${ }^{3,5}$

The students should have a clear perception of both the merits and demerits of a speciality which they are opting for in their post graduate study. Various promising aspects of a speciality can attract more students towards it. On the other hand, thorough understanding of the drawbacks can reduce the number of dropouts in post graduate course. Hence it becomes imperative for the medical students to have an accurate perception about the multimodal dimensions of a speciality. This will not only help them to consider their career choices in future years but also ensure high level of patient care.

Total 63 postgraduate students pursuing anaesthesiology under the West Bengal University of Health Sciences participated in this study. The response rate was $100 \%$ because the questionnaire was given and collected back personally by the members of the research team. Thirteen students were excluded from the study as they already had previous exposure to anaesthesiology in the form of house-jobs or diploma in this discipline. So, data collected from 50 students were analysed finally.

In this study, we have found that the students were not fully informed about the wide spread domain of anaesthesiology. They were well aware of the anaesthesiologist's involvement in patient care during intra-operative period and in intensive care unit. But the role of the anaesthesiologists in the preoperative as well as postoperative patient management was poorly recognised. Only $16 \%$ ascribed the preoperative check-up as a function of the anaesthesiologist and $74 \%$ students mentioned that preoperative optimisation of a patient with cardiac disorder should be done by a cardiologist. Similar results were also obtained in an Irish study. ${ }^{5}$ On the other hand, majority of the students knew that the anaesthesiologists interact with the patients preoperatively and communicate with their relatives. Lack of knowledge about the anaesthesiologist's functions may be attributed to limited undergraduate exposure. It is indicative of the fact that during rotational internship in surgery department, the students have observed that the anaesthesiologists examined the patient preoperatively.
But their exact role in preoperative patient optimisation and care remain unknown. Inadequate undergraduate anaesthesiology exposure was also evident in a recent study on post-graduate students. ${ }^{6}$

Exposure to infectious agents, ionising and non-ionising radiation, anaesthetic gases, diathermy and laser smoke inhalation, manual handling injuries, substance abuse and adverse foetal and maternal outcomes are well documented occupational hazards. ${ }^{7,8}$ But, a large number of students $(48 \%)$ were unaware of any health hazards associated with the practice of anaesthesiology.

There was no statistically significant difference regarding the perception of the students in respect to their choice of this subject as first preference (except in the question number 2). It is well documented that the anaesthesiologists suffer from high work-related exhaustion and mental stress. ${ }^{9}$ Significantly greater number of students choosing this subject as first preference also considered this discipline stressful ( $p=0.010$ ). This finding is quite encouraging because the students are attracted toward this speciality despite its stressful nature.

Adudu OP et al found that anaesthesiologist's involvement in fluid management and trauma care was poorly recognised by the undergraduate students. ${ }^{3}$ But, in this study, most of the students ascribed the above functions to the anaesthesiologists. It may be suggestive of the fact that the perception of the undergraduate students was different from those of the postgraduate anaesthesiology students.

The administrative as well as the academic activities of the anaesthesiologists remain unknown to a large number of students. A large portion of them did not know whether an anaesthesiologist could be in charge of hospital administration or whether a PhD can be done in this subject. The students may feel more interested if these aspects of the discipline can be highlighted.

This fact is well established that the patients and the undergraduate medical students have poor perception about anaesthesiologists. ${ }^{1-4}$ But the postgraduate students of this discipline are likely to have a better perception as they have already chosen their career as anaesthesiologists. But this study revealed that most of the students including those choosing this speciality as first preference $(n=14)$ have a poor perception. They considered this discipline surgeon dependent, stressful and unrecognised. It may indicate their ignorance towards the domain of the anaesthesiologists outside the operating room.

The universities and teaching institutions should modify the undergraduate curriculum so that the students remain well exposed and have a better understanding of this subject. During internship, students should be involved in preoperative patient preparation, postoperative care, resuscitation, pain clinic and intensive care unit. We would also suggest that various societies of anaesthesiologists 
take part in improving the student's attitude regarding widespread domain of this discipline.

Relatively small sample size and inclusion of the students pursuing anaesthesiology under a single university were the limitations of this study.

\section{Conclusion}

It is concluded that there is an inconsistent perception among the new post graduate students of anaesthesiology regarding this discipline. It specifically identifies various potential areas of improvement including modification of curriculum, elaborated teaching role and active participation of various professional organisations. These can reform the notion of the undergraduate students, thereby helping them to make a sound professional judgement.

Conflict of interest: None declared

\section{References}

1. Mathur SK, Dube SK, Jain S. Knowledge about Anaesthesia and Anaesthesiologist Amongst General Population in India. Indian J Anaesth 2009;53:179-86.

2. Naithani U, Purohit D, Bajaj P. Public Awareness about Anaesthesia and Anaesthesiologist: A Survey. Indian J Anaesth 2007;51:420-6.

3. Adudu OP, Le NH, Devito I, Campbell FA, Levine MF. Medical student impressions of anesthesiology and anesthesiologists. Can J Anesth 2010;57:792-3.

4. Adudu OP. What impressions do medical students of the University of Benin have about anaesthesia and anaesthesiologists? Niger Postgrad Med J 2005;12:250-4.

5. Smith A, Mannion S, Iohom G. Irish Medical Students Knowledge and Perception of Anaesthesia. Education in Medicine Journal 2013;5:e83-8.

6. Shrestha A. Anaesthesia education in Nepal - What residents think. JSAN 2014;1:65-9.

7. Thomas I, Anthony J. Occupational hazards of anaesthesia. Continuing Education in Anaesthesia, Critical Care \& Pain 2006;6:182-7.

8. Bajwa SJ, Kaur J. Risk and safety concerns in anaesthesiology practice: The present perspective. Anesth Essays Res 2012;6:14-20.

9. Riad W, Mansour A, Moussa A. Anesthesiologists workrelated exhaustion: A comparison study with other hospital employees. Saudi J Anaesth 2011;5:244-7. 